\title{
HPV infection in women with and without cervical cancer in Conakry, Guinea
}

\author{
N Keita', GM Clifford,2, M Koulibaly ${ }^{3}$, K Douno', I Kabba ${ }^{3}$, M Haba ${ }^{3}$, BS Sylla ${ }^{2}$, FJ van Kemenade ${ }^{4}$, \\ PJF Snijders ${ }^{4}$, CJLM Meijer ${ }^{4}$ and S Franceschi ${ }^{2}$
}

'Department of Obstetrics and Gynaecology, Centre Hospitalier Universitaire de Donka, B.P. 92 I, Conakry, Guinea; ${ }^{2}$ International Agency for Research on Cancer, 150 cours Albert Thomas, 69372 Lyon cedex 08, France; ${ }^{3}$ Department of Pathology, Centre Hospitalier Universitaire de Donka, B.P. 921 ,

Conakry, Guinea; ${ }^{4}$ Department of Pathology, Vrije University Medical Center, Postbus 7057, 1007 MB Amsterdam, The Netherlands

BACKGROUND: Cervical cancer incidence in western Africa is among the highest in the world.

METHODS: To investigate human papillomavirus (HPV) infection in Guinea, we obtained cervical specimens from 83I women aged 18-64 years from the general population of the capital Conakry and from 77 locally diagnosed invasive cervical cancers (ICC). Human papillomavirus was detected using a GP5 + 16 + PCR-based assay.

RESULTS: Among the general population, the prevalence of cervical abnormalities was $2.6 \%$ by visual inspection and $9.5 \%$ by liquidbased cytology. Fourteen of 15 high-grade squamous intraepithelial lesions were visual inspection-negative. Human papillomavirus prevalence was 50.8\% (32.1\% for high-risk types) and relatively constant across all age groups. Being single or reporting $\geqslant 3$ sexual partners was significantly associated with HPV positivity. HPVI 6 was the most common type, both among the general population (7.3\%) and, notably in ICC (48.6\%). HPV45 (18.6\%) and HPVI8 (I4.3\%), the next most common types in ICC, were also more common in ICC than in HPV-positive women with normal cytology from the general population.

CONCLUSION: The heavy burden of HPV infection and severe cervical lesions in Guinean women calls for new effective interventions. Sixty-three per cent of cervical cancers are theoretically preventable by HPVI6//8 vaccines in Guinea; perhaps more if some cross-protection exists with HPV45.

British Journal of Cancer (2009) I 0I, 202-208. doi:I0.1038/sj.bjc.6605 I40 www.bjcancer.com

Published online 16 June 2009

(C) 2009 Cancer Research UK

Keywords: cervical cancer; human papillomavirus; prevalence; Guinea; Africa

The Republic of Guinea in western Africa has a population of approximately 9.4 million, of which 2 million live in the capital of Conakry. The country shows high birth rates $(5.8$ children per woman) and communicable diseases, notably malaria, which predominate as causes of death. Estimates of cervical cancer incidence and mortality rates in western Africa are among the highest in the world (Ferlay et al, 2004), and in Conakry, cervical cancer is by far the most common malignancy in women (Koulibaly et al, 1997).

Establishing the viral aetiology of cervical cancer has raised the hopes for primary and secondary prevention through human papillomavirus (HPV) vaccination (Kahn and Burk, 2007) and HPV DNA test-based screening (Cuzick et al, 2006), respectively. The rationale and planning of such measures require populationbased epidemiological data on overall and type-specific HPV prevalence in women with and without cancer. To this end, the International Agency for Research on Cancer (IARC) has carried out surveys in representative samples of women worldwide (Clifford et al, 2005).

We report on HPV prevalence survey among a representative sample of the general female population in Conakry, Guinea, as

* Correspondence: Dr GM Clifford; E-mail: clifford@iarc.fr

Received 30 March 2009; revised II May 2009; accepted 26 May 2009; published online 16 June 2009 well as in a corresponding sample of Guinean women with invasive cervical cancer (ICC).

\section{MATERIALS AND METHODS}

Study methods were similar to those used for earlier IARC HPV Prevalence Surveys (Clifford et al, 2005). In the study area of Gbessia Port, a densely populated district of Conakry, we aimed to enrol approximately 100 women from the general population in each 5-year age group between 15 and 19 and 60 and 64 years. All mentally and physically competent women, regardless of their marital and sexual activity status, were eligible. Women were enumerated at their homes by local community workers and invited to the Gbessia Port Health Centre (Centre de Santé de Gbessia Port) between April and December 2006 to participate in the study.

Of the 1725 invited women, $440(25.5 \%)$ did not accept the invitation, mainly because they apparently did not understand the need for gynaecological examination in the absence of symptoms. Acceptance was similar in all the age groups, but owing to the age structure of the population, relatively few women over 44 years of age could be invited (life expectancy of women in Guinea was estimated in 2004 to be 55 years [www.who.int]). In addition, among the 462 women below age 25 years who accepted the 
invitation to the study clinic, 213 (of whom 148 were self-declared virgins) were unwilling to undergo a pelvic examination, and opted to provide only a blood sample. Hence, no cervical cell specimen was collected for these 213 women; an additional 73 women aged 25 years or older did not undergo a pelvic examination mainly because of heavy menstrual bleeding.

A structured questionnaire was administered by one of the five nurses in the local dialect covering socio-demographic characteristics, reproductive and menstrual factors, sexual habits, including those of the participants and their husbands' and lifetime use of contraceptive methods.

A total of 999 women underwent a pelvic examination by one of the three midwives. Three women presented with an advanced cervical cancer that did not allow for collection of an adequate cervical cell sample. Among the remaining 996, a sample of exfoliated cervical cells for liquid-based cytology and HPV testing was collected. A cytobrush, after insertion into the endocervical canal, was rotated gently at $180^{\circ}$ to collect cells, was then placed with its cellular material in a vial containing PreservCyt media (Cytyc-Hologic, Marlborough, MA, USA). The cervix was then inspected with acetic acid (VIA) and visual inspection with Lugol's iodine (VILI), with results reported according to the IARC criteria (Sankaranarayanan and Wesley, 2003).

Slides for liquid-based cytology were prepared using a Thin Prep 3000 processor (Cytyc-Hologic), stained according to manufacturer's instructions and read at the Department of Pathology at the Vrije University Medical Center, Amsterdam, the Netherlands. Cytological diagnosis was formulated according to CISOE-A standards and was translated into the Bethesda 2001 terminology system (Bulk et al, 2004). Confirmatory biopsies, when available, were read (MK) in the Centre National d'Anatomie Pathologique, Centre Hospitalier Universitaire (CHU) de Donka.

Women presenting with ICC at the gynaecological clinic of the CHU de Donka, Conakry, were identified between January 2006 and March 2007. The collection of a tumour biopsy for study purposes was possible for all 99 women diagnosed with ICC; most were classified as stage II ( 51 women) or III (44 women). Biopsies were fixed with buffered formalin, embedded in paraffin $(\mathrm{MH})$, then read (MK) in the Centre National d'Anatomie Pathologique, CHU de Donka. HIV testing was available for 41 women with ICC, of which eight (19.5\%) were HIV-positive; among 19 women with ICC below age 45 years, six were HIV-positive.

All participants, whether from the HPV prevalence survey or those with ICC, signed informed consent forms according to the recommendations of the IARC and the CHU de Donka ethical review committees, both of which approved the study.

HPV testing was performed on exfoliated cervical cells and ICC biopsies in the Department of Pathology at the Vrije University Medical Center. DNA was extracted from the PreservCyt sample using magnetic beads (Macheri-Nagel, Düren, Germany) on a robotic system (Hamilton, Germany), according to the manufacturer's instructions. Invasive cervical cancer biopsies were sectioned using a 'sandwich' approach, whereby inner tumour sections were destined for HPV testing and outer sections for histological confirmation of tumour tissue. One or more five $1 \mathrm{M}$ sections representing approximately $1 \mathrm{~cm}^{2}$ of tissue were predigested with Proteinase $\mathrm{K}$ after which DNA was extracted using magnetic beads (Macheri-Nagel, Germany).

Beta-globin PCR analysis was performed first to confirm the presence of human DNA in all specimens (Roda Husman et al, 1995). The overall presence of HPV DNA was determined by performing a general primer GP5 $+16+-$ mediated PCR, which permits the detection of a broad spectrum of genital HPV types at the subpicogram level (Jacobs et al, 2000). Human papillomavirus positivity was assessed by hybridisation of PCR products in an enzyme immunoassay using two HPV oligoprobe cocktails that, together, detect the following $44 \mathrm{HPV}$ types: HPV6, 11, 16, 18, 26, $30,31,32,33,34,35,39,40,42,43,44,45,51,52,53,54,55,56,57$,
$58,59,61,64,66,67,68,69,70,71$ (equivalent to CP8061), 72, 73, 81 (equivalent to CP8304), 82 (IS39 and MM4 subtypes), 83 (equivalent to MM7), 84 (equivalent to MM8), cand85, 86, cand89 (equivalent to CP6108) and JC9710. Subsequent HPV typing was performed by reverse line blot hybridisation of PCR products, as described earlier (van den Brule et al, 2002). In this typing format, all aforementioned HPV types were individually genotyped, except for the uncommon HPV types 32, 83, 84, 85, 86 and JC9710. Oligoprobes representing the latter types were loaded as a pool on the reverse line blots and consequently were genotyped as a pool. Human papillomavirus types considered high risk for this analysis that comprised HPV16, 18, 31, 33, 35, 39, 45, 51, 52, 56, 58, 59, 68, 73 and 82 (Muñoz et al, 2003); all other HPV types were considered low risk.

\section{Statistical analysis}

Odds ratios (ORs) for HPV positivity and corresponding 95\% confidence intervals (CIs) were calculated by means of unconditional logistic regression equations, adjusted for age group (15-24, $25-34,35-44,45-54,55-64$ years), marital status (never- or evermarried) and lifetime number of sexual partners $(1,2$ and $\geqslant 3)$, as appropriate. The statistical significance of trends for ORs was assessed by considering the categorical variable as a continuous variable in the logistic model. Prevalence ratios and corresponding 95\% CIs were used to compare the relative frequency of the most common HPV types in HPV-positive women with ICC with that among cytologically normal HPV-positive women from the HPV prevalence survey.

\section{RESULTS}

Of 996 women who provided cervical cell samples, 84 had inadequate HPV DNA results (77 $\beta$-globin-negative, seven missing), and an additional 81 had inadequate cytology, leaving 831 women with valid results for both HPV and cytology. Among them, 79 (9.5\%) had abnormal cytological findings, including 48 $(5.8 \%)$ atypical squamous cells of undetermined significance (ASCUS), 16 (1.9\%) low-grade squamous intraepithelial lesions (LSIL) and 15 (1.8\%) HSIL.

Overall HPV prevalence was 50.8\% (78.5\% and $47.9 \%$ among women with and without cervical abnormalities, respectively, Table 1). The corresponding age-standardised prevalence to the world population was $51.5 \%$ (95\% CI: $48.0-55.0)$. In total, 275 (33.1\%) women had single-type and 147 (17.7\%) had multiple-type infections. Prevalence of high-risk and low-risk types $(32.1,30.5 \%$, respectively) was similar. The commonest high-risk types with normal cytology were HPV16 (6.7\%), 45 (4.7\%), 52 (4.0\%), and 18, 35 and 58 (3.2\% each). HPV66, 42 and 81 were the most commonly detected low-risk types. HPV16 was also the commonest type (13.9\%) among women with cervical abnormalities, of whom $59.5 \%$ had high-risk types. The prevalence of high-risk HPV types in women with HSIL or worse was $73.3 \%$ (data not shown).

Twenty-one women had abnormalities suspected at VIA/VILI. The correlation between the results of VIA/VILI and those of liquid-based cytology and HPV testing was poor (Table 2). VIA/ VILI identified one HSIL (that was shown to be ICC by histology), but missed 14 of 15 HSIL, 15 of 16 LSIL and all 48 ASCUS. The proportion of suspected abnormalities at VIA/VILI did not differ significantly between high-risk HPV-positive $(7 / 264 ; 2.7 \%)$ and high-risk HPV-negative $(14 / 558 ; 2.5 \%)$ women $\left(\chi_{1}^{2}=0.0146\right.$, $P=0.904)$.

Of the 21 women with suspected abnormalities at VIA/VILI, 17 accepted referral to colposcopy and 10 had colposcopy-directed biopsies, none of which showed lesions except the aforementioned ICC. Repeated attempts were also made after cytological findings became available (i.e., approximately one year and a half after the 
Table I Prevalence of HPV types by cytological findings and overall among 831 women (Conakry, Guinea, 2006-2008)

\begin{tabular}{|c|c|c|c|c|c|c|c|c|c|}
\hline \multirow[b]{2}{*}{ HPV type } & \multicolumn{3}{|c|}{ Normal cytology $(N=752)$} & \multicolumn{3}{|c|}{ Abnormal cytology $(N=79)$} & \multicolumn{3}{|c|}{ Total $(N=83 I)$} \\
\hline & Single & Multiple & Total (\%) & Single & Multiple & Total (\%) & Single & Multiple & Total (\%) \\
\hline High-risk HPV+ & 118 & 102 & $220(29.3)$ & 23 & 24 & $47(59.5)$ & $|4|$ & 126 & $267(32.1)$ \\
\hline Low-risk HPV+ & 123 & 96 & $219(29.1)$ & 11 & 23 & $34(43.0)$ & 134 & 119 & $253(30.5)$ \\
\hline 18 & 13 & II & $24(3.2)$ & । & $2^{b}$ & $3(3.8)$ & 14 & 13 & $27(3.3)$ \\
\hline 31 & 5 & 5 & $10(1.3)$ & 2 & $3^{b}$ & $5(6.3)$ & 7 & 8 & $15(1.8)$ \\
\hline 33 & 11 & 11 & $22(2.9)$ & $4^{\mathrm{b}}$ & $5^{\mathrm{a}}$ & $9(11.4)$ & 15 & 16 & $31(3.7)$ \\
\hline 35 & 9 & 15 & $24(3.2)$ & 2 & 2 & $4(5.1)$ & 11 & 17 & $28(3.4)$ \\
\hline 39 & 4 & 3 & $7(0.9)$ & 0 & 0 & 0 & 4 & 3 & $7(0.8)$ \\
\hline 45 & 11 & 24 & $35(4.7)$ & $4^{\mathrm{a}}$ & 1 & $5(6.3)$ & 15 & 25 & $40(4.8)$ \\
\hline 51 & 5 & 9 & $14(1.9)$ & 0 & $2^{b}$ & $2(2.5)$ & 5 & 11 & $16(1.9)$ \\
\hline 73 & 3 & 5 & $8(1.1)$ & 0 & 4 & $4(5.1)$ & 3 & 9 & $12(1.4)$ \\
\hline 82 & 3 & 3 & $6(0.8)$ & I & i & $2(2.5)$ & 4 & 4 & $8(1.0)$ \\
\hline Subtotal & 118 & 165 & $283-$ & 23 & 36 & $59-$ & 141 & 201 & $342-$ \\
\hline \multicolumn{10}{|l|}{ Low-risk infections } \\
\hline 6 & 2 & 7 & $9(1.2)$ & 0 & 2 & $2(2.5)$ & 2 & 9 & $11(1.3)$ \\
\hline 11 & 2 & 1 & $3(0.4)$ & 0 & 0 & 0 & 2 & i & $3(0.4)$ \\
\hline 26 & 2 & 2 & $4(0.5)$ & 0 & 0 & 0 & 2 & 2 & $4(0.5)$ \\
\hline 30 & 4 & 4 & $8(1.1)$ & I & 0 & I (I.3) & 5 & 4 & $9(1.1)$ \\
\hline 34 & 0 & 1 & $1(0.1)$ & 0 & 0 & 0 & 0 & । & $1(0.1)$ \\
\hline 40 & 0 & 3 & $3(0.4)$ & 0 & । & । (1.3) & 0 & 4 & $4(0.5)$ \\
\hline 42 & 11 & 9 & $20(2.7)$ & 0 & $4^{b}$ & $4(5.1)$ & 11 & 13 & $24(2.9)$ \\
\hline 43 & 2 & 10 & $12(1.6)$ & 0 & 1 & I (1.3) & 2 & 11 & $13(1.6)$ \\
\hline 72 & 8 & 10 & $18(2.4)$ & 0 & 0 & 0 & 8 & 10 & $18(2.2)$ \\
\hline 81 & 15 & 8 & $23(3.1)$ & 0 & 0 & 0 & 15 & 8 & $23(2.8)$ \\
\hline CP6108 & 3 & 3 & $6(0.8)$ & 0 & 0 & 0 & 3 & 3 & $6(0.7)$ \\
\hline Low-risk cocktail $^{c}$ & 22 & 32 & $54(7.2)$ & 2 & $11^{\mathrm{a}}$ & $13(16.5)$ & 24 & 43 & $67(8.1)$ \\
\hline Subtotal & 93 & 150 & $243-$ & 8 & 35 & $43-$ & 101 & 185 & $286-$ \\
\hline$x$ & 30 & 0 & $30(4.0)$ & $3^{b}$ & 0 & $3(3.8)$ & 33 & 0 & $33(4.0)$ \\
\hline Total infections & 241 & 315 & $556-$ & 34 & 71 & $105-$ & 275 & 386 & $661-$ \\
\hline
\end{tabular}

${ }^{a}$ Includes two HSIL. 'Includes one HSIL. Includes HPV32,83,84,85,86,JC97। 0. HPV = human papillomavirus; HSIL = high-grade squamous intraepithelial lesions; $N=$ number: $X=$ uncharacterised type.

initial visit) to recall the 14 women who had no abnormality detected at VIA/VILI but HSIL found at liquid-based cytology. Three women, however, had moved far from Conakry, one was not found at her address, one had died of a disease other than cervical cancer and one was in the third trimester of pregnancy. Of the eight biopsies taken, one was inadequate, three showed cervical intraepithelial neoplasia 1 and the other four showed no cervical lesion.

Figure 1A and B show, respectively, the prevalence of HPV (any HPV type, HPV16 and/or 18 and any high-risk types and low-risk types, separately) and of VIA/VILI and cytological abnormalities by age group. Human papillomavirus prevalence was $56.1 \%$ among women younger than 25 years, and dropped to $45.3 \%$ in women aged 35-44 years, before increasing again up to $55 \%$ in women aged 45 years or older. Age-specific patterns were similar for the prevalence of HPV16 and/or 18 and any high-risk type. When 157 women who had never been married $(75.8 \%$ of whom were $<25$ years) were excluded, HPV prevalence below age 25 years decreased to $46.3 \%$ (Figure 1A). VIA/VILI and cytological abnormalities increased up to age 35-44 years and then declined.

Table 3 shows the relationship between HPV positivity and various characteristics of participants according to two different models. In the age-adjusted model, significant differences in HPV positivity were observed by age group (OR for 35-44vs $<25$ years $=0.65 ; 95 \% \mathrm{CI}: 0.44-0.95$ ), marital status (OR in single $v s$ married women $=1.60 ; 95 \% \mathrm{CI}: 1.04-2.45$ ) and number of lifetime sexual partners (OR for $\geqslant 3$ vs 1 partner $=1.71$; 95\% CI: $1.03-$ 2.84). These three associations were slightly attenuated in the 
Table 2 Cytological abnormalities and detection of high-risk HPV types by presence of suspected abnormalities at VIA/VILI among 822 women ${ }^{a}$ (Conakry, Guinea, 2006-2008)

\section{VIA/VILI}

\begin{tabular}{|c|c|c|c|c|c|c|}
\hline \multirow[b]{2}{*}{ Cytology } & \multicolumn{3}{|c|}{ Normal } & \multicolumn{3}{|c|}{ Abnormal } \\
\hline & High-risk HPV- & High-risk HPV+ & All & High-risk HPV - & High-risk HPV+ & All \\
\hline ASCUS & 24 & 24 & 48 & 0 & 0 & 0 \\
\hline LSIL & 4 & 11 & 15 & 0 & I & I \\
\hline HSIL & $3^{\mathrm{b}}$ & 11 & 14 & $1^{c}$ & 0 & i \\
\hline All & 544 & 257 & 801 & 14 & 7 & 21 \\
\hline
\end{tabular}

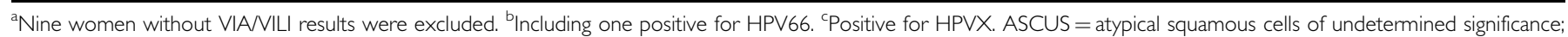

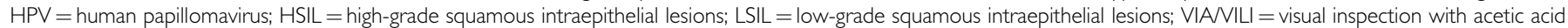
or Lugol's iodine.
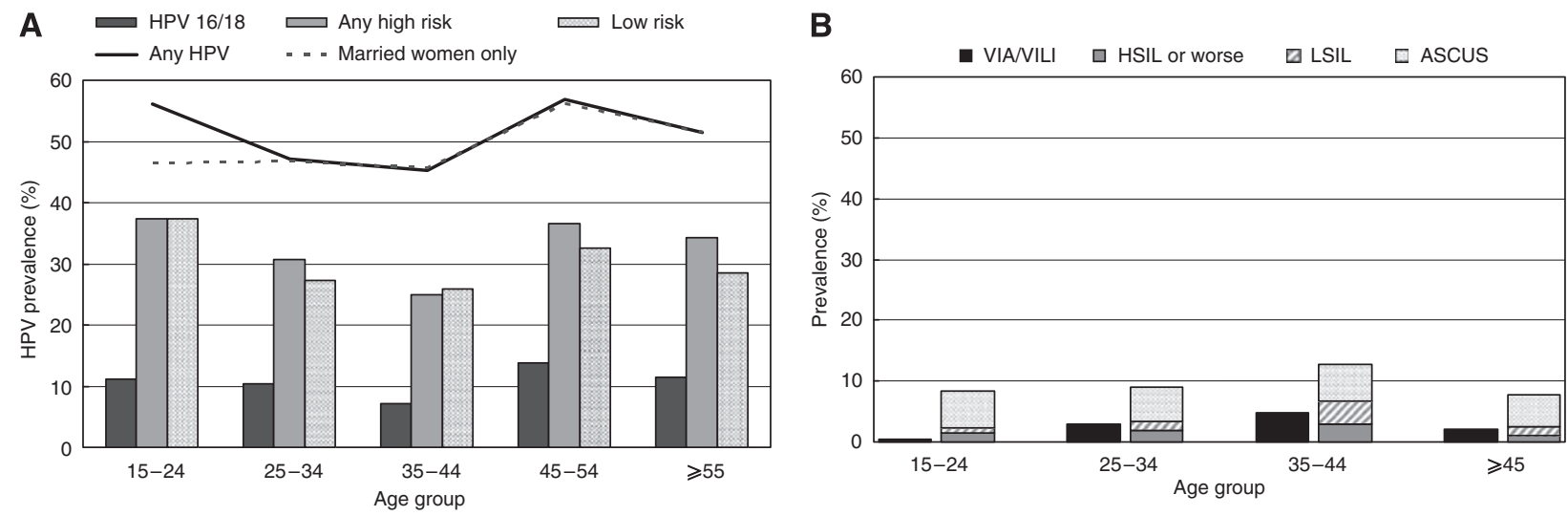

Figure I Age-specific prevalence of (A) HPV DNA by HPV type(s) overall (83I women) and among married women only (674 women) (B) cervical abnormalities at VIAVILI and liquid-based cytology. Conakry, Guinea, 2006-2008. ASCUS, atypical squamous cells of undetermined significance; HPV, human papillomavirus; HSIL, high-grade squamous intraepithelial lesion; LSIL, low-grade squamous intraepithelial lesion; VIA, visual inspection with acetic acid; VILI, visual inspection with Lugol's iodine.

model additionally adjusted, as appropriate, for marital status and sexual partners.

Education, number of births, age at first sexual intercourse, husbands' polygamy or extra-marital sexual relationships and lifetime use of hormonal contraceptives were unrelated to HPV positivity in either adjustment model (Table 3) as were smoking habits, condom use (reported by only 16 women) and history of spontaneous or induced abortions (data not shown). Only six $(0.7 \%)$ participants reported having had previous cervical cancer screening.

Beta-globin-negative ICC biopsies (22) were excluded; among the remaining 77 ICC biopsies with valid HPV results, 8 were adeno- and the rest were squamous-cell carcinoma. The median age of women with ICC was 45 years (range: $23-80$ years). Seven ICC biopsies, including one adenocarcinoma, were HPV-negative. Type-specific HPV prevalence in $70 \mathrm{HPV}$-positive ICC and 360 cytologically normal HPV-positive women from the HPV prevalence survey are compared in Table 4 . HPV16 was found in 34 (48.6; 95\% CI: $36.4-60.8 \%$ ) HPV-positive ICC biopsies. The next commonest types were HPV45 (18.6; 95\% CI: $10.3-29.7 \%)$ and 18 (14.3; 95\% CI: 7.1 -24.7\%). Prevalence ratios in women with ICC $v s$ cytologically normal women were 3.5 (95\% CI: $2.2-5.5)$ for HPV16, 2.1 (95\% CI: 0.9-4.6) for HPV18; 1.9 (95\% CI: 0.9-3.7) for HPV45 and 0.8 (95\% CI: $0.5-1.2)$ for high-risk types other than 16 or 18. Multiple-type infections were much less common in HPVpositive women with ICC than in HPV-positive women with normal cytology (Table 4). Among the five ICC biopsies deriving from HIV-infected women with a valid HPV result, HPV16, 45, 18 were found in two, two and one woman, respectively.

\section{DISCUSSION}

Our large study, the first on HPV infection in Guinea, showed a very high $(50.8 \%)$ prevalence of $\mathrm{HPV}$, and nearly no history of cervical cancer screening. Approximately one-third of women in our survey were infected with high-risk HPV types and four prevalent ICC were discovered.

The age-standardised HPV prevalence we found in Conakry $(51.5 \%)$ was considerably higher than that observed in earlier studies performed using the same HPV testing protocol in areas at high risk for cervical cancer such as South America $(12-18 \%)$ and India (17\%) or even another western African population in Nigeria (27\%) (Franceschi et al, 2006). It is also of the highest HPV prevalence reported in any study in western Africa (Xi et al, 2003; Wall et al, 2005; Lack et al, 2005) or other parts of sub-Saharan Africa (de Sanjosé et al, 2007; Castellsagué et al, 2008), with the exception of those that included only, or a majority of, HIV-positive women (Sahasrabuddhe et al, 2007). Differences in age and sensitivity of PCR testing methods, however, limit the direct comparability with studies other than the IARC HPV Prevalence Surveys.

Nearly half of study women reported having two sexual partners or more in their lifetime, and over two-thirds reported husband's 
Table 3 ORs for HPV positivity and corresponding 95\% Cls according to selected characteristics among 83I women (Conakry, Guinea, 2006-2008)

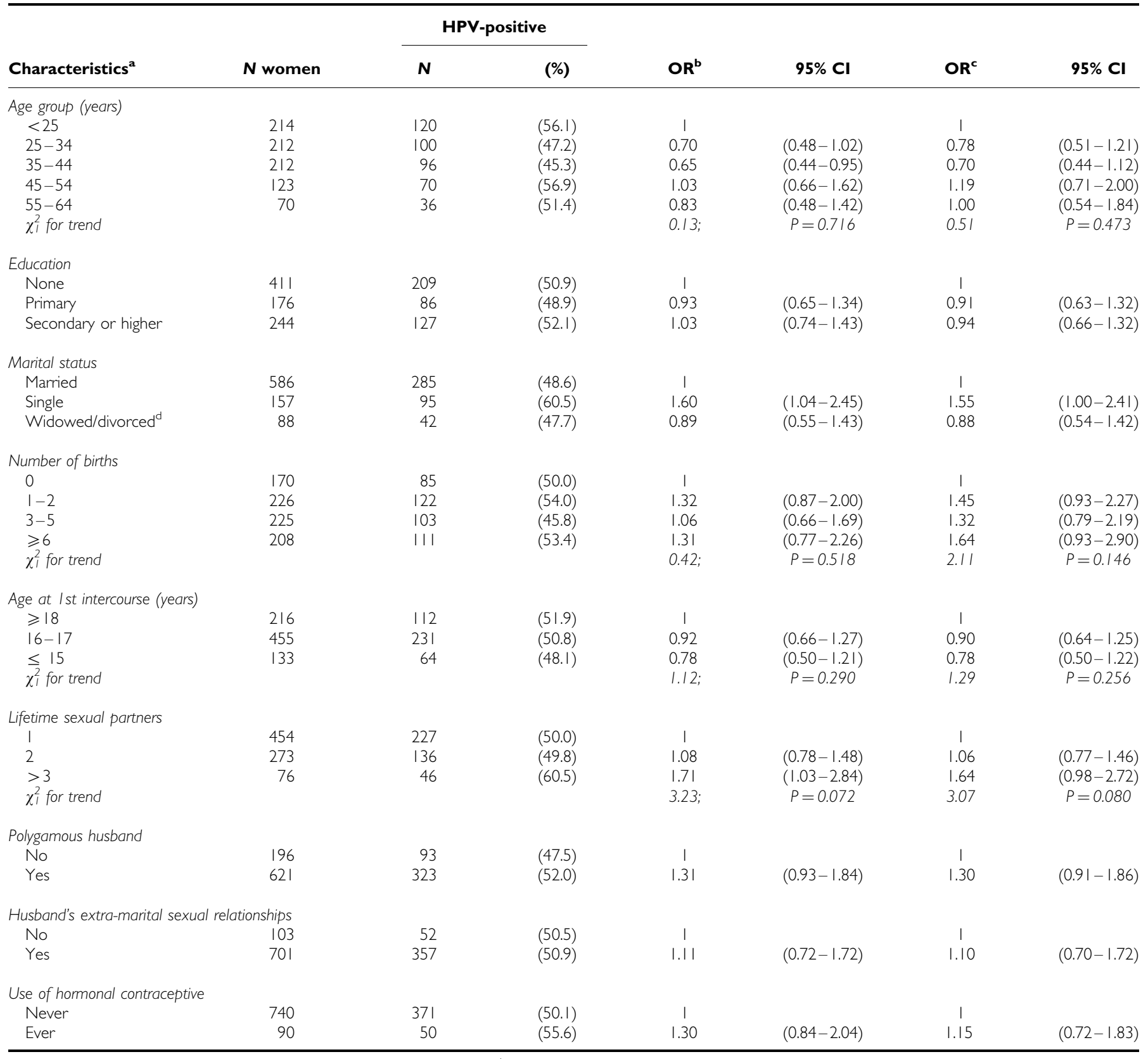

${ }^{a}$ Some figures do not add up to the total because of a few missing values. ${ }^{b}$ Adjusted for age group, as appropriate. ${ }^{c}$ Adjusted for age group, ever/never married and lifetime number of sexual partners $(1,2,>2)$, as appropriate. Including nine divorced women. $\mathrm{Cl}=$ confidence intervals; $\mathrm{HPV}=$ human papillomavirus; $\mathrm{N}=$ number; $\mathrm{OR}=$ odds ratios.

polygamy or extra-marital relationships. These indicators of high-risk sexual behaviour can help to explain the elevated HPV prevalence in this study. Conversely, on account of the very high frequency of HPV infection that emerged in our study, it is not surprising that HPV-negative and -positive women did not differ by various characteristics, including education level, except for a moderately increased infection risk in single women and women who reported three sexual partners or more in their lifetime.

An influence of undetected HIV infection on high HPV prevalence in our study women cannot be ruled out, as the protocol of the IARC HPV Prevalence Surveys does not include HIV testing. In 2004, a survey of pregnant women estimated the prevalence of HIV to be $4.2 \%$ nationally, and $6 \%$ in Gbessia Port, Conakry; this seemed to be fairly uniform across age groups, implying a well-established epidemic, but was somewhat higher among unmarried women (9.2\%) (Ministère de la Santé Publique, 2005). HIV infection among tested women with ICC (20\%) was high considering the limited life expectancy of people with HIV/ AIDS during the study period (Franceschi and Jaffe, 2007).

One of the main aims of the IARC HPV Prevalence Surveys concerns the variations of age-specific and type-specific HPV prevalence by geographical region. The age-specific curve of HPV prevalence in Guinea resembled the age curves reported earlier in Nigeria (Thomas et al, 2004), India (Franceschi et al, 2005) and China (Dai et al, 2006; Li et al, 2006; Wu et al, 2007), but differed from the steep decrease in prevalence seen by age in high-resource countries (Franceschi et al, 2006; De Vuyst et al, 2009). A modest peak in women below age 25 years in Guinea was accounted for by 
Table 4 Prevalence of selected HPV types in 70 HPV-positive women with ICC ${ }^{a}$ and 360 HPV-positive women with normal cytology (Conakry, Guinea, 2006-2008)

\begin{tabular}{|c|c|c|c|}
\hline & $\begin{array}{c}\text { ICC } \\
(N=70)\end{array}$ & $\begin{array}{c}\text { Normal cytology } \\
(N=360)\end{array}$ & $\begin{array}{l}\text { ICC:normal } \\
\text { cytology }\end{array}$ \\
\hline HPV type & Total (\%) & Total (\%) & $\begin{array}{c}\text { Prevalence ratio } \\
(95 \% \mathrm{Cl})\end{array}$ \\
\hline 16 & $34(48.6)$ & $50(13.9)$ & $3.5(2.2-5.5)$ \\
\hline 18 & $10(14.3)$ & $24(6.7)$ & $2.1(0.9-4.6)$ \\
\hline $16 / 18$ & $44(62.9)$ & $73(20.3)$ & $3.1(2.1-4.6)$ \\
\hline \multicolumn{4}{|l|}{ Other high-risk types } \\
\hline 33 & $2(2.9)$ & $22(6.1)$ & $0.5(0.05-1.9)$ \\
\hline 35 & $3(4.3)$ & $24(6.7)$ & $0.6(0.1-2.1)$ \\
\hline 39 & $2(2.9)$ & $7(1.9)$ & $1.5(0.1-7.7)$ \\
\hline 45 & $13(18.6)$ & $35(9.7)$ & $1.9(0.9-3.7)$ \\
\hline $\begin{array}{l}\text { Any high-risk type other } \\
\text { than } 16 / 18\end{array}$ & $25(35.7)$ & $169(46.9)$ & $0.8(0.5-1.2)$ \\
\hline Low-risk type & $2^{\mathrm{b}}(2.9)$ & $219(60.8)$ & $0.05(0.006-0.2)$ \\
\hline$x$ & $2(2.9)$ & $30(8.3)$ & $0.3(0.04-1.4)$ \\
\hline Multiple infections & $3^{c}(4.3)$ & $119(33.1)$ & $0.1(0.03-0.4)$ \\
\hline
\end{tabular}

${ }^{a}$ Seven HPV-negative ICC are not included. 'Includes one single HPV30 infection. 'Two HPVI6+45 and one HPVI6+69. Cl=confidence interval; HPV=human papillomavirus; ICC $=$ invasive cervical carcinoma.

the participation of unmarried women in this age group (Franceschi et al, 2006). By contrast, in IARC HPV Prevalence Surveys in India and China it was considered socially unacceptable to invite unmarried women (Franceschi et al, 2005; Dai et al, 2006; Li et al, 2006; Wu et al, 2007). In some earlier studies from subSaharan Africa, HPV prevalence also remained high (Kuhn et al, 2000; Thomas et al, 2004; Wall et al, 2005) or even increased (Xi et al, 2003) in middle and old age, whereas peaks in young women were reported by other investigators (Serwadda et al, 1999; Womack et al, 2000; Castellsagué et al, 2001; De Vuyst et al, 2003; Baay et al, 2004).

With respect to the relative importance of different HPV types, HPV16 was the commonest type overall, that is, $13.9 \%, 17.7 \%$ and $48.6 \%$, respectively, in cytologically normal and abnormal women and in women with ICC (Clifford et al, 2005; Smith et al, 2007). Noticeably, however, the high proportion of HPV45 (18.6; 95\% CI: $10.3-29.7 \%)$ is consistent with a meta-analysis of HPV type distribution in ICC from western Africa (Smith et al, 2007). Elsewhere, HPV45, a high-risk type that, similar to HPV18, belongs to the $\alpha-7$ species, is usually less frequently detected than HPV18 in cytologically normal women (de Sanjosé et al, 2007) and women with ICC (Smith et al, 2007).

On account of the lack of experienced cytologists and HPV testing in Conakry, we relied on VIA/VILI for the immediate clinical management of study women from the HPV prevalence survey. Despite the substantial experience of study midwives in visual inspection (Sankaranarayanan et al, 2004), the majority (77/79) of cytological abnormalities later showed by liquid-based cytology were VIA/VILI-negative (including 14/15 HSIL), and $61.9 \%$ of abnormalities suspected at VIA/VILI were found in cytologically normal women who were negative for high-risk HPV types. None of the 10 biopsies taken among VIA/VILI-positive women, with the exception of one ICC case, showed cervical intraepithelial neoplasia of any grade.

Major strengths of our study include the large number of women, high participation, reliance on high-quality HPV testing and liquid-based cytology, and presence of a concurrent series of women with ICC drawn from the same study area. Limitations include the lack of information on HIV status and the relatively high proportion of $\beta$-globin-negative samples in the HPV prevalence survey, and of HPV-negative findings in paraffinembedded ICC biopsies. Most important, the lack of prompt histological confirmation of abnormalities and of random biopsies did not allow us to accurately estimate sensitivity and specificity of different methods. A prolonged curfew in 2007 delayed not only the shipment of cervical cell samples to Europe and, hence, the availability of cytological and HPV findings, but also the recall of women. Substantial population mobility and scarcity of pathology staff in Conakry also hampered the appropriate work up of screening positive women.

The very heavy burden of HPV infection and severe cervical lesions in Guinea calls for new effective interventions. The quality of VIA/VILI should be greatly improved, or other types of screening used (e.g., rapid HPV test, Qiao et al, 2008), whereas screen-and-treat approaches should be encouraged for recalling women. With respect to the potential benefit of vaccination, the fraction of ICC preventable in Guinea (62.9; 95\% CI: $50.5-74.1)$ by a vaccine including HPV16/18, is compatible with the worldwide estimate (Smith et al, 2007), but would be substantially improved if some cross-protection between HPV16/18 and HPV45 was confirmed to exist (Barr and Sings, 2008; Jenkins, 2008).

\section{ACKNOWLEDGEMENTS}

The authors thank Dr Rengaswamy Sankaranarayanan for valuable comments. This work was supported by the Bill and Melinda Gates Foundation, Seattle, WA, USA (grant number 35537).

\section{Conflict of interest}

The authors declare no conflict of interest.

\section{REFERENCES}

Baay MF, Kjetland EF, Ndhlovu PD, Deschoolmeester V, Mduluza T, Gomo E, Friis H, Midzi N, Gwanzura L, Mason PR, Vermorken JB, Gundersen SG (2004) Human papillomavirus in a rural community in Zimbabwe: the impact of HIV co-infection on HPV genotype distribution. J Med Virol 73: $481-485$

Barr E, Sings HL (2008) Prophylactic HPV vaccines: new interventions for cancer control. Vaccine 26: 6244-6257

Bulk S, Van Kemenade FJ, Rozendaal L, Meijer CJ (2004) The Dutch CISOE-A framework for cytology reporting increases efficacy of screening upon standardisation since 1996. J Clin Pathol 57: $388-393$
Castellsagué X, Klaustermeier J, Carrilho C, Albero G, Sacarlal J, Quint W, Kleter B, Lloveras B, Ismail MR, de Sanjosé S, Bosch FX, Alonso P, Menendez C (2008) Vaccine-related HPV genotypes in women with and without cervical cancer in Mozambique: burden and potential for prevention. Int J Cancer 122: 1901 - 1904

Castellsagué X, Menendez C, Loscertales MP, Kornegay JR, dos Santos F, Gomez-Olive FX, Lloveras B, Abarca N, Vaz N, Barreto A, Bosch FX, Alonso P (2001) Human papillomavirus genotypes in rural Mozambique. Lancet 358: $1429-1430$

Clifford GM, Gallus S, Herrero R, Muñoz N, Snijders PJ, Vaccarella S, Anh PT, Ferreccio C, Hieu NT, Matos E, Molano M, Rajkumar R, 
Ronco G, de Sanjosé S, Shin HR, Sukvirach S, Thomas JO, Tunsakul S, Meijer CJ, Franceschi S, IARC HPV Prevalence Surveys Study Group (2005) Worldwide distribution of human papillomavirus types in cytologically normal women in the International Agency for Research on Cancer HPV Prevalence surveys: a pooled analysis. Lancet 366: 991- 998

Cuzick J, Clavel C, Petry KU, Meijer CJ, Hoyer H, Ratnam S, Szarewski A, Birembaut P, Kulasingam S, Sasieni P, Iftner T (2006) Overview of the European and North American studies on HPV testing in primary cervical cancer screening. Int J Cancer 119: $1095-1101$

Dai M, Bao YP, Li N, Clifford GM, Vaccarella S, Snijders PJF, Huang RD, Sun LX, Meijer CJLM, Qiao YL, Franceschi S (2006) Human papillomavirus infection in Shanxi Province, People's Republic of China: a population-based study. Br J Cancer 95: 96-101

de Sanjosé S, Diaz M, Castellsagué X, Clifford GM, Bruni L, Muñoz N, Bosch FX (2007) Worldwide prevalence and genotype distribution of cervical human papillomavirus DNA in women with normal cytology: a meta-analysis. Lancet Infect Dis 7: 453-459

De Vuyst H, Clifford GM, Li N, Franceschi S (2009) HPV infection in Europe. Eur J Cancer (in press)

De Vuyst H, Steyaert S, Van Renterghem L, Claeys P, Muchiri L, Sitati S, Vansteelandt S, Quint W, Kleter B, Van Marck E, Temmerman M (2003) Distribution of human papillomavirus in a family planning population in Nairobi, Kenya. Sex Transm Dis 30: 137-142

Ferlay J, Bray F, Pisani P, Parkin DM (2004) Globocan 2002: Incidence, Mortality and Prevalence Worldwide [CD-ROM]. International Agency for Research on Cancer: Lyon

Franceschi S, Herrero R, Clifford GM, Snijders PJ, Arslan A, Anh PT, Bosch FX, Ferreccio C, Hieu NT, Lazcano-Ponce E, Matos E, Molano M, Qiao YL, Rajkumar R, Ronco G, de Sanjosé S, Shin HR, Sukvirach S, Thomas JO, Meijer CJ, Muñoz N, IARC HPV Prevalence Surveys Study Group (2006) Variations in the age-specific curves of human papillomavirus prevalence in women worldwide. Int J Cancer 119: 2677-2684

Franceschi S, Jaffe H (2007) Cervical cancer screening of women living with HIV: a must in the post-ART era. Clin Infect Dis 45: 510-513

Franceschi S, Rajkumar R, Snijders PJF, Arslan A, Mahé C, Plummer M, Sankaranarayanan R, Cherian J, Meijer CJLM, Weiderpass E (2005) Papillomavirus infection in rural women in southern India. $\mathrm{Br} \mathrm{J}$ Cancer 92: $601-606$

Jacobs MV, Walboomers JM, Snijders PJ, Voorhorst FJ, Verheijen RH, Fransen-Daalmeijer N, Meijer CJ (2000) Distribution of 37 mucosotropic HPV types in women with cytologically normal cervical smears: the age-related patterns for high-risk and low-risk types. Int J Cancer 87: $221-227$

Jenkins D (2008) A review of cross-protection against oncogenic HPV by an HPV-16/18 AS04-adjuvanted cervical cancer vaccine: importance of virological and clinical endpoints and implications for mass vaccination in cervical cancer prevention. Gynecol Oncol 110: S18-S25

Kahn JA, Burk RD (2007) Papillomavirus vaccines in perspective. Lancet 369: $2135-2137$

Koulibaly M, Kabba IS, Cisse A, Diallo SB, Diallo MB, Keita N, Camara ND, Diallo MS, Sylla BS, Parkin DM (1997) Cancer incidence in Conakry, Guinea: first results from the Cancer Registry 1992-1995. Int J Cancer 70: $39-45$

Kuhn L, Denny L, Pollack A, Lorincz A, Richart RM, Wright TC (2000) Human papillomavirus DNA testing for cervical cancer screening in low-resource settings. J Natl Cancer Inst 92: 818-825

Lack N, West B, Jeffries D, Ekpo G, Morison L, Soutter WP, Walraven G, Boryseiwicz L (2005) Comparison of non-invasive sampling methods for detection of HPV in rural African women. Sex Transm Infect 81: $239-241$

Li LK, Dai M, Clifford GM, Yao WQ, Arslan A, Li N, Shi JF, Snijders PJ, Meijer CJ, Qiao YL, Franceschi S (2006) Human papillomavirus infection in Shenyang City, People's Republic of China: a population-based study. Br J Cancer 95: 1593 - 1597

Ministère de la Santé Publique (2005) Enquête nationale de surveillance sentinelle du VIH et de la syphilis chez les femmes enceintes. Ministère de la Santé Publique: Conakry

Muñoz N, Bosch FX, de Sanjosé S, Herrero R, Castellsagué X, Shah KV, Snijders PJ, Meijer CJ (2003) Epidemiologic classification of human papillomavirus types associated with cervical cancer. $N$ Engl J Med 348: $518-527$

Qiao YL, Sellors JW, Eder PS, Bao YP, Lim JM, Zhao FH, Weigl B, Zhang WH, Peck RB, Li L, Chen F, Pan QJ, Lorincz AT (2008) A new HPV-DNA test for cervical-cancer screening in developing regions: a cross-sectional study of clinical accuracy in rural China. Lancet Oncol 9: 929-936

Roda Husman AM, Snijders PJ, Stel HV, van den Brule AJ, Meijer CJ, Walboomers JM (1995) Processing of long-stored archival cervical smears for human papillomavirus detection by the polymerase chain reaction. $\mathrm{Br}$ J Cancer 72: $412-417$

Sahasrabuddhe VV, Mwanahamuntu MH, Vermund SH, Huh WK, Lyon MD, Stringer JS, Parham GP (2007) Prevalence and distribution of HPV genotypes among HIV-infected women in Zambia. $\mathrm{Br} J$ Cancer 96: $1480-1483$

Sankaranarayanan R, Basu P, Wesley RS, Mahe C, Keita N, Mbalawa CC, Sharma R, Dolo A, Shastri SS, Nacoulma M, Nayama M, Somanathan T, Lucas E, Muwonge R, Frappart L, Parkin DM (2004) Accuracy of visual screening for cervical neoplasia: Results from an IARC multicentre study in India and Africa. Int J Cancer 110: $907-913$

Sankaranarayanan R, Wesley R (2003) A Practical Manual on Visual Screening for Cervical Neoplasia. IARC Technical Publication No. 41 IARC Press: Lyon

Serwadda D, Wawer MJ, Shah KV, Sewankambo NK, Daniel R, Li C, Lorincz A, Meehan MP, Wabwire-Mangen F, Gray RH (1999) Use of a hybrid capture assay of self-collected vaginal swabs in rural Uganda for detection of human papillomavirus. J Infect Dis 180: 1316-1319

Smith JS, Lindsay L, Hoots B, Keys J, Franceschi S, Winer R, Clifford GM (2007) Human papillomavirus type distribution in invasive cervical cancer and high-grade cervical lesions: a meta-analysis update. Int $J$ Cancer 121: $621-632$

Thomas JO, Herrero R, Omigbodun AA, Ojemakinde K, Ajayi IO, Fawole A, Oladepo O, Smith JS, Arslan A, Munoz N, Snijders PJ, Meijer CJ, Franceschi S (2004) Prevalence of papillomavirus infection in women in Ibadan, Nigeria: a population-based study. Br J Cancer 90: 638-645

van den Brule AJ, Pol R, Fransen-Daalmeijer N, Schouls LM, Meijer CJ, Snijders PJ (2002) GP5+/6+ PCR followed by reverse line blot analysis enables rapid and high-throughput identification of human papillomavirus genotypes. J Clin Microbiol 40: 779-787

Wall SR, Scherf CF, Morison L, Hart KW, West B, Ekpo G, Fiander AN, Man S, Gelder CM, Walraven G, Borysiewicz LK (2005) Cervical human papillomavirus infection and squamous intraepithelial lesions in rural Gambia, West Africa: viral sequence analysis and epidemiology. $\mathrm{Br} J$ Cancer 93: 1068 - 1076

Womack SD, Chirenje ZM, Gaffikin L, Blumenthal PD, McGrath JA Chipato T, Ngwalle S, Munjoma M, Shah KV (2000) HPV-based cervical cancer screening in a population at high risk for HIV infection. Int $J$ Cancer 85: $206-210$

Wu RF, Dai M, Qiao YL, Clifford GM, Liu ZH, Arslan A, Li N, Shi JF, Snijders PJ, Meijer CJ, Franceschi S (2007) Human papillomavirus infection in women in Shenzhen City, People's Republic of China, a population typical of recent Chinese urbanisation. Int J Cancer 121: 1306-1311

Xi LF, Toure P, Critchlow CW, Hawes SE, Dembele B, Sow PS, Kiviat NB (2003) Prevalence of specific types of human papillomavirus and cervical squamous intraepithelial lesions in consecutive, previously unscreened, West-African women over 35 years of age. Int J Cancer 103: 803-809 